\title{
DRUG UTILIZATION PATTERN IN THROAT INFECTION IN OUTPATIENT DEPARTMENT OF GOVERNMENT MEDICAL COLLEGE AND CPR HOSPITAL, KOLHAPUR
}

\author{
Ajit B. Lokare1, Jayprakash B. Ramanand², Rama R. Bhosale3, Satish C. Shitole ${ }^{4}$, Choure Balwant K5, Puram Nitin N6 \\ ${ }^{1}$ Associate Professor, Department of ENT, Rajashree Chatrapati Shahu Maharaj Government Medical College, Kolhapur. \\ 2Dean, Rajashree Chatrapati Shahu Maharaj Government Medical College, Kolhapur. \\ ${ }^{3}$ Lecturer, Department of Pharmacology, Rajashree Chatrapati Shahu Maharaj Government Medical College, Kolhapur. \\ ${ }^{4}$ Lecturer, Department of Ophthalmic, Rajashree Chatrapati Shahu Maharaj Government Medical College, Kolhapur. \\ ${ }_{5}^{5}$ Lecturer, Department of Pharmacology, Rajashree Chatrapati Shahu Maharaj Government Medical College, Kolhapur. \\ ${ }^{6}$ Lecturer, Department of Pharmacology, Rajashree Chatrapati Shahu Maharaj Government Medical College, Kolhapur.
}

\section{ABSTRACT}

\section{BACKGROUND}

Drug utilization studies are used to analyse different aspects of the use of drugs and to implement methods of improving therapeutic quality. This study was conducted to study drug prescription pattern in outpatient department of Government Medical College and C.P.R. Hospital, Kolhapur, which is one of the important medical college in Western Maharashtra.

\section{METHODS}

One thousand prescriptions were screened and analysed as per the study parameters from OPD of Government Medical College and C.P.R. Hospital, Kolhapur. Study parameters like demographic profile of the patient like age, sex and diagnosis were recorded. Also groups of drugs commonly prescribed, number of drugs per patient, drug profile and drawbacks of prescription if any were recorded and analysed.

\section{RESULTS}

Most common group of drugs prescribed by ENT Surgeon was Antibiotic (26.94\%) followed by Antihistamines (25.87\%), Analgesics (17.50\%) and Multivitamins (12.02\%). The average number of drugs prescribed per patient was four; the average number of analgesic was one. The incidence of polypharmacy was common occurrence and some prescriptions had small drawbacks like absence of diagnosis, absence of doctor's signature, etc.

\section{CONCLUSIONS}

We conclude that most of the prescriptions, which were analysed at R.C.S.M. Government Medical College and C.P.R. Hospital, Kolhapur, were according to the standard norms of WHO prescriptions and also most of the drugs prescribed were from the list of essential drug list, but still there is scope for improvement in prescription pattern.

\section{KEYWORDS}

C.P.R. Hospital, Drug Utilisation, Outpatient Department, Throat Infection.

HOW TO CITE THIS ARTICLE: Lokare AB, Ramanand JB, Bhosale RR, et al. Drug utilization pattern in throat infection in outpatient department of government medical college and CPR Hospital, Kolhapur. J. Evolution Med. Dent. Sci. 2016;5(56):3844-3846, DOI: $10.14260 /$ jemds/2016/880

\section{INTRODUCTION}

A prescription-based survey is considered to be one of the most effective methods to assess and evaluate the prescribing attitude of physicians and prescription-based drug utilization studies are more meaningful to observe the prescribing attitude of physicians with the aim to provide drugs rationally. The results of these types of studies, which were carried out at different health care centres are used to evaluate and analyse the medical, social and economic outcomes of the drug therapy. ${ }^{1}$ The World Health Organization (WHO) addressed drug utilization as "The marketing, distribution, prescription and use of drugs in a society considering its consequences,

Financial or Other, Competing Interest: None.

Submission 07-06-2016, Peer Review 02-07-2016,

Acceptance 07-07-2016, Published 13-07-2016.

Corresponding Author:

Dr. Ajit B. Lokare,

\#249/A/1/10 Yashada Apartment

Near Warana Colony, E Ward,

Nagala Park,

Kolhapur-416003.

E-mail: lokareajit@yahoo.com

DOI: $10.14260 /$ jemds $/ 2016 / 880$ medical, social and economic."2 Drug utilization studies can provide very important information at a reasonable price on the costs and effects either harmful or beneficial of drugs. Such studies provide much useful information including indirect data on morbidity, the pharmaceutical component of the treatment cost of an illness, therapeutic compliance, the incidence of adverse drug reactions and the effectiveness of drug consumption. ${ }^{3}$ Drug utilization data may be used to produce crude estimates of disease prevalence also. ${ }^{4}$

Although, a number of studies have been undertaken to study the drug prescribing pattern of different medical and dental colleges. ${ }^{4,5,6,7,8,9}$ but no study was conducted to evaluate drug utilization pattern of R.C.S.M. Government Medical College and C.P.R. Hospital, Kolhapur, which is an important medical college of Western Maharashtra.

Upper Respiratory Tract Infections which are characterized by a triad of symptoms namely running nose, cough and fever constitute the major symptomatology of children attending the paediatrics outpatient clinics of any hospital. Though the condition is self-limiting and may times caused by a virus, recurrent attacks of nasotonsillar 
pharyngitis lead to a distinct morbidity.

A child with recurrent upper respiratory tract infections receives various combinations of potent antibacterial agents, which are not only expensive but also potentially toxic producing unwanted side-effects and hence not safe for frequent use. Many antibiotics has been extensively reported to have effective antibacterial and anti-inflammatory properties in the management of acute and or recurrent upper respiratory tract infections, sinusitis and otitis media. Many times Upper Respiratory Tract Infections involved in sore throat is a term that includes any painful condition in the oropharynx. There are many causes of acute or chronic inflammation of the throat that lead to various clinical situations and may lead to many disorders. Sore throat is usually caused by bacteria or a virus or due to some allergies. Smoking and air pollution can cause sore throat. To control these conditions, symptomatic relief may be achieved by using medicines such as mouth gargles, NSAIDs, lozenges, etc. Sometimes analgesics and antipyretic therapy are additional requirements.

Pharyngitis also occurs due to sore throat. Pharyngitis presents with sore throat, pain radiating to the ears and dysphagia. Sometimes there is fever. Fever is more commonly associated with group-A beta-haemolytic streptococci (Streptococcus pyogenes). Pharyngitis caused by streptococci should be treated with caution. Other causes include Mycoplasma, Epstein-Barr virus, Adenovirus, Influenza virus, Arcanobacterium haemolyticum, gonococcal pharyngitis and others.

Patients with sore throat are advised to rest the voice and take some soothing agents to help relieve the pain and irritation. Gargling with warm salt water and sucking throat lozenges can help ease sore throat. They should be advised to avoid spicy foods, because it will irritate the throat further. Smoking also irritates the throat and it can be responsible for recurrent infections. Sore throat can be treated initially with local antiseptic and anti-inflammatory medications.

\section{METHODS}

Permission from the Dean, Head of the Institute, was taken to carry out this study.

It is a prospective, randomized, observational study which was carried out over a period of three months. Prescriptions of the patients by attending the outpatient department of R.C.S.M. Government Medical College, Kolhapur and those visited to dispensary were selected. Prescriptions were scanned by mobile and all scanned prescriptions were examined with reference to study parameters. Accordingly, a sample of thousand $(n=1000)$ prescriptions of either sex were randomly selected for prescription pattern analysis.

Collected prescriptions were analysed based on the objective of the study. The age and sex of the patients, groups of drugs commonly prescribed, number of drugs per patient, drug profile and drawbacks of prescription if any were recorded and analysed.

\section{RESULTS}

Data of patients $(n=1000)$ was analysed according to the study parameters. Total number of drugs prescribed in these patients was 4324. Therefore, average number of drugs per patient was approximately 4 (i.e. 4324). The demographic profile of the patients was found to be as follows: Male patients were more than female patients and patients of age group 2040 years were more than other groups, i.e. $32.7 \%$ (Table No. 1 ).

Most common group of drugs prescribed by ENT Surgeon was Antibiotic (26.94\%) followed by Antihistamines (25.87\%), Analgesics (17.50\%) and Multivitamins (12.02\%). (Table No. 2). Most common analgesics which were used are Paracetamol (Tablet and syrup), Diclofenac (Tablet $50 \mathrm{mg}$ and $100 \mathrm{mg}$ ). Most common antimicrobials which were used are Capsule Amoxicillin, Tablet Septran, Tablet Cipro-Tz (Ciprofloxacin + Tinidazole), Capsule Doxycycline, Gentamycin ear-drops, Ciprofloxacin ear drops, Ciprofloxacin + Dexamethasone ear drops. Most common multivitamins, which were used are Tablet Ferofolla, Tablet Apcal-. The incidence of polypharmacy was also common occurrence and maximum no. of drugs which were prescribed per prescription was four; $34 \%$ of prescriptions had 3 drugs, $46.5 \%$ had 4 drugs and $4.1 \%$ had 5 drugs per prescription (Table 4 ).

Various problems were also encountered in these prescriptions. Most common error found was duration of treatment not written (13.1\%). Other errors such as absence of diagnosis and absence of signature of doctor were also present (Table 5).

\section{DISCUSSION}

Drug utilization studies are used to analyse different aspects of the use of drugs and to implement ways of improving therapeutic quality, keeping in mind the fact that health resources are very limited. ${ }^{6}$ The present study was conducted to study drug utilization pattern in outpatient department of R.C.S.M. Government Medical College and C.P.R. Hospital, Kolhapur which is an important medical college and hospital in Western Maharashtra. The most common groups of drugs prescribed by physicians were analgesics, antimicrobials followed by multivitamins.

Most common group of drugs was antimicrobials and most common antimicrobials used were penicillin group of drugs, quinolones and macrolides. Factors like resistance, sensitivity and contraindications of antimicrobials were taken into consideration while prescribing these antibiotics. Appropriate use of antibiotics is necessary to prevent emergence of drug resistance and if possible these antibiotics should be used after culture sensitivity testing. Most of the cases are viral in nature and may not need antibiotics. ${ }^{10}$ Also attention was given to the age of the patient. For example, quinolones were never prescribed to children.

Second most common group of drugs was antihistamines and most common antihistamines used were CPM, Levocetirizine and Fexofenadine.

Third common group of drugs prescribed was analgesics and most common analgesic was paracetamol. Analgesics are used for various conditions associated with fever, pain and inflammation.11 Analgesics were prescribed by doctors by considering adverse effects, contraindications of drugs and also by considering patient related factors like age, sex, etc. In India, most of the patients attended to outpatient department of government medical colleges are from poor families and most of them are having nutrition related problems like anaemia, various vitamin and mineral deficiencies.9,11 Also vitamins and minerals are required for women who came for antenatal care checkup. Therefore, multi-vitamins group of drugs is common prescribed group among poor socioeconomic families. In present data, most common 
multivitamins prescribed were iron, vitamin $\mathrm{B}_{12}$, folic acid, calcium, vitamin D, etc.

Average number of drugs per prescription is an important index of prescription audit. ${ }^{12}$ In present study, total thousand prescriptions were studied and total number of drugs of all these prescriptions was 4324 and average drugs per patient were four. But there is a recommendation of two drugs per patient. ${ }^{6}$ Increase in the number of drugs per prescription may increase the risk of drug-drug interactions, may lead to unwanted side effects and also increases the prescribing and dispensing errors. ${ }^{5}$ In our study, Fixed Dose Combinations (FDC) were also prescribed. Potential drawbacks of FDC include inflexible fixed dose ratio, incompatible pharmacokinetics, increased toxicity and physician's ignorance of contents. 5 Therefore, use of fixed dose combinations should be discouraged unless strictly necessary.

There were certain drawbacks of this study. Patients who attended outpatient department, but not visited to dispensary were not included in this study. Also patients of AIDS and tuberculosis were excluded from the study as these patients received their medicine from ART and RNTCP centres of same medical college, respectively.

\begin{tabular}{|c|c|c|}
\hline & Age Distribution & Number (\%) \\
\hline 1 & Children (0-12 years) & $240(24.0 \%)$ \\
\hline 2 & Adolescents (13-19 years) & $298(29.8 \%)$ \\
\hline 3 & Adults (20-40 years) & $327(32.7 \%)$ \\
\hline 4 & Adults (40-60 years) & $112(11.2 \%)$ \\
\hline 5 & Above 60 years & $23(2.3 \%)$ \\
\hline & Sex Distribution & Number (\%) \\
\hline 1 & Males & $625(62.5 \%)$ \\
\hline 2 & Females & $375(37.5 \%)$ \\
\hline \multicolumn{3}{|c|}{ Table 1: Demographic Profile of Patients } \\
\hline
\end{tabular}

\begin{tabular}{|c|c|c|}
\hline & Category of Drugs & Number of Drugs (\%) \\
\hline 1. & Antibiotics & $1165(26.94 \%)$ \\
\hline 2. & Antihistamines & $1119(25.87 \%)$ \\
\hline 3. & Analgesics & $757(17.50 \%)$ \\
\hline 4. & Multivitamins & $520(12.02 \%)$ \\
\hline 5. & Antacid and other & $763(17.64 \%)$ \\
\hline \multicolumn{2}{|c|}{ Table 2: Common Categories of Drugs } \\
Prescribed to Outpatients \\
\hline
\end{tabular}

\begin{tabular}{|c|c|}
\hline $\begin{array}{c}\text { Prescription Containing } \\
\text { Number of Drugs }\end{array}$ & $\begin{array}{c}\text { Number of } \\
\text { Prescriptions (\%) }\end{array}$ \\
\hline One & $25(2.5 \%)$ \\
\hline Two & $129(12.9 \%)$ \\
\hline Three & $340(34.0 \%)$ \\
\hline Four & $465(46.5 \%)$ \\
\hline Five & $41(4.1 \%)$ \\
\hline Table 3: Number of Drugs Prescribed per Prescription \\
\hline
\end{tabular}

\begin{tabular}{|c|c|c|}
\hline & $\begin{array}{c}\text { Problem } \\
\text { Description }\end{array}$ & $\begin{array}{c}\text { Number of } \\
\text { Prescriptions (\%) }\end{array}$ \\
\hline 1. & Diagnosis not written & $24(2.4 \%)$ \\
\hline 2. & $\begin{array}{l}\text { Duration of treatment } \\
\text { not written }\end{array}$ & $131(13.1 \%)$ \\
\hline 3. & Sex not written & $0(0 \%)$ \\
\hline 4. & Age not written & $0(0 \%)$ \\
\hline 5. & Date not written & $0(0 \%)$ \\
\hline 6. & OPD number absent & $0(0 \%)$ \\
\hline 7. & $\begin{array}{l}\text { Signature of doctor } \\
\text { absent }\end{array}$ & $18(1.8 \%)$ \\
\hline 8. & Total & $173(17.3 \%)$ \\
\hline
\end{tabular}

\section{CONCLUSIONS}

Taken together, we can conclude that most of the prescriptions which were analysed at R.C.S.M. Government Medical College and C.P.R. Hospital, Kolhapur, were according to the standard norms of WHO prescriptions and also most of the drugs prescribed were from the list of essential drug list. But still there is scope for improvement in prescription pattern.

\section{REFERENCES}

1. Tiwari H, Kumar A, Kulkarni SK. Prescription monitoring of antihypertensive drug utilisation at the Punjab university health centre in India. Singapore Med J 2004;45(3):117-20.

2. WHO Expert Committee. The selection of essential drugs, technical report series no. 615. Geneva. World Health Organization 1977.

3. Sacristán JA, Soto J. Drug utilisation studies as tools in health economics. Pharmacoeconomics 1994;5(4):299312.

4. Kulkarni MD, Baig MS, Hussaini SA, et al. Drug utilization pattern in OPD of government dental college and hospital, Aurangabad. Int J Basic Clin Pharmacol 2013;2(1):69-70.

5. Abidi A, Gupta S, Kansal S, et al. Prescription auditing and drug utilization pattern in a tertiary care teaching hospital of western UP. Int J Basic Clin Pharm 2012;1(3):184-90.

6. WHO. How to investigate drug use in health facilities. WHO/DAP 1993. World Health Organisation. Geneva. 1993;1:87.

7. Provencio RM. Drug utilization studies. Revista de Neurologia 1996;24(128):397-9.

8. Gama H. Drug utilization studies. Arq Med 2008;22:69-74.

9. Laporte JR, Porta M, Capella D. Drug utilization studies: a tool for determining the effectiveness of drug use. British Journal of Clinical Pharmacology 1983;16(3):301-4.

10. Rang HP, Dale MM, Ritter JM, et al. Rang and Dale's Pharmacology. 7th edn. Elsevier, Churchill Livingstone publication, 2012:519-20.

11. Goodman, Gilman G. The Pharmacological Basis of Therapeutics. $12^{\text {th }}$ edn. McGraw-Hill publication, 2011:1022-5.

12. Gupta M, Malhotra S, Jain S, et al. Pattern of prescription of non-steroidal anti-inflammatory drugs in orthopaedic outpatient clinic of a north Indian tertiary care hospital. Indian J Pharmacol 2005;37(6):404-5. 